\title{
Potential use of lignobiomass for sugar production
}

\begin{abstract}
Nowadays, continuously increasing petroleum costs and dependence upon fossil fuel resources create major attention to focused on alternative energy resources. Fuel resources and the energy source is the highest priority since trillions of people all over the world use it in the sector of transportation, electricity, food and industrial manufacture. The need for alternative sources of bio-energy was expected to increase sharply in the future. The abundant and free raw material in the form of lignocellulosic biomass has been considered as an alternative for fossil fuel. In this short review, the potential of lignocellulosic biomass to produce bio-sugar are highlighted. This short review highlights and provides an overview of various pretreatment methods used to degrade the cellulosic material challenges to convert lignocellulosic biomass into fermentable sugar.
\end{abstract}

Keywords: bioprocess fermentation, method of pretreatment, lignocellulosic biomass, sugar production
Volume 3 Issue 6 - 2017

\author{
Zulkefflizan Jamaludin,' Madihah Md Salleh,2 \\ Adibah Yahya ${ }^{2}$ \\ 'Department of Bioscience and Medical Engineering, Universiti \\ Teknologi Malaysia, Malaysia \\ ${ }^{2}$ Environmental and Biotechnology Research Group, Universiti \\ Teknologi Malaysia, Malaysia
}

\begin{abstract}
Correspondence: Madihah Md Salleh, Environmental and Biotechnology Research Group, Sustainability Research Alliance, Universiti Teknologi Malaysia, 8 13 I 0 Skudai Johor, Malaysia, Tel
\end{abstract} +6075557546, Email madihah@fbb.utm.my

Received: May 05, 2017 | Published: September 15, 2017

\section{Introduction}

\section{Lignocellulosic biomass}

Lignocellulosic biomass including woody crops, forest residues (fallen branches, saw dust, leaves, etc.), agricultural residues (sugarcane bagasse, corn stover, rice straw, rice husk, sweet sorghum, oil palm waste etc.), ${ }^{1}$ are most abundant, inexpensive and renewable carbon sources available in the form of plant biomass. Since lignocellulosic are abundant and cheaper make it be an attractive alternative material for bioethanol production and could reduce the possible conflict between land use for food production and energy feedstock production. ${ }^{2}$ The huge quantities of these residues are generated and largely unutilized and can cause a problem to the environment through the burning of the crop and unused lignocellulosic. The reuse of lignocellulose biomass can reduce the greenhouse gas emissions and lead to healthier environmental.

\section{Type of biomass}

The variation of cellulose, hemicellulose and lignin content in lignocellulosic depends on whether it is derived from hardwood and softwood. ${ }^{3}$ The principal component of softwood is glucomannan while hardwood is glucuronoxylan. The difference in term of backbone sugar in softwood is mannose with a side chains of glucose and galactose but backbone sugar in hardwood is xylan with side chains of arabinose and glucuronic acid. Generally, composition of lignocellulose components of softwood are about $45-50 \%$ of cellulose, $25-35 \%$ of hemicellulose and $25-35 \%$ of lignin whereas in hardwood biomass is about $40-55 \%$ of cellulose, $24-40 \%$ of hemicellulose and $18-25 \%$ of lignin. ${ }^{4}$

\section{Component of biomass}

Lignocellulosic made up of microfibrils of cellulose embedded in an amorphous matrix of hemicellulose and lignin. ${ }^{5}$ These three types of polymers are strongly bonded to one another make it have a complex structure and difficult to breakdown to generate fermentable sugars. Celluloses are polysaccharide consisting of 8000 to 12000 residues D-glucose linked by $\beta-1,4$ glycoside bonds with a general formula of $\left(\mathrm{C}_{6} \mathrm{H}_{10} \mathrm{O}_{5}\right) \mathrm{n}$. The linear structure of the cellulose chain allows the formation of both intermolecular and intramolecular hydrogen bonds resulting in the aggregation of chains into crystalline fibrils of 36 cellulose chain. ${ }^{6}$ Hemicellulose is a heterogeneous polysaccharides which are located between lignin and cellulose fiber and composed of different monosaccharides units such as D-glucose, L-rhamnose, D-galactose, D-mannose, L-fucose, D-xylose, L-arabinose, D-glucuronic acid, D-galacturonic acid 4-O-methyl-D-glucuronic acid. Hemicellulose polymer chains have short branches and are amorphous. The amorphous morphology of the hemicellulose are partially soluble to water and solutes. Lignin is a complex network formed by polymerization of phenyl propane units. The three monomers in lignin are p-coumaryl alcohol, coniferyl alcohol, and sinapyl alcohol and linked through alkyl-aryl, alkyl-alkyl and aryl-aryl ether bonds and it able to form covalent bonds to some hemicelluloses. ${ }^{7}$ Lignin is hydrophobic and highly resistant towards chemical and biological degradation. There is an enzyme that plays important role in degrading the structure of lignocellulose.

\section{Pretreatment of biomass}

The structure of lignocellulosic biomass has been selected in nature to resist the microbial degradation in order to maintain the structure. The effectiveness of lignocellulosic biomass hydrolysis and pretreatment has long been considered to change the structure of cellulosic biomass to make cellulose more accessible. Pretreatments are classified into physical pretreatment, chemical pretreatment, physico-chemical pretreatment, and biological pretreatment. Physical pretreatment used such as milling, grinding, chipping and extrusion to increase the accessible surface area, size of spores, and decrease the crystallinity of the biomass. Chemical pretreatment used concentrated or dilute of acid and alkali to increase internal surface area and porosity. Physico-chemical pretreatment is combination of both physical and chemical pretreatment with the aid of an alkali or acid such as steam explosion and ammonia fiber explosion process which can increase surface area and partial degradation of hemicellulose. In biological pretreatment processes, microorganisms such as brown, white, and soft rot fungi are used to degrade lignin and hemicellulose in lignocellulosic biomass. ${ }^{8}$ 


\section{Challenges using lignobiomass}

The challenges to convert sugar from lignobiomass is rate and yield of lignocellulose conversion into fermentable sugars is low, due to the resistance crystalline structure of cellulose and the physical barrier formed by the lignin surrounding the cellulose. ${ }^{9}$ Many lignocellulosic biomasses have been study and tested for bioethanol production, but the large-scale production of bioethanol has not been yet applied because the cost of production is high based on current technologies. The challenges use of biomass for biofuel production depends on four important factors whereas physical and chemical properties of the biomass, pretreatment method, efficient microorganisms, and conditions of optimization process. ${ }^{10}$

\section{Discussion}

Several pretreatment methods have been studied for lignocellulosic biomass in order to increase the production of the enzyme, sugar and etc. All the pretreatment methods are done to make the lignocelluloses are accessible to the enzymatic attack. The crystallinity of cellulose and its accessible surface area and protection by lignin and hemicellulose are the main difficulty to achieve an efficient hydrolysis. Advantages for most of the pretreatment methods were depending on the type of biomass used. However, effective conversion of lignocellulosic biomass to sugars is not limited on the selection of most efficient pretreatment or hydrolysis method. Factors such as biomass type, the size of substrates, initial moisture, initial $\mathrm{pH}$, temperature, and type of microorganisms used can affect the outcome of the fermentation.

\section{Conclusion}

The fossil fuel and environmental crisis forcing the world to evaluate the current situation and started to utilized or finding alternatives uses of natural and renewable resources. In this matter, lignocellulose biomass has a great potential as a renewable source to overcome the excessive dependence on petroleum for liquid fuels. Bioethanol and biofuels are produced from simple sugars that are derived from various source of lignocellulosic biomass. Advanced research in biotechnologies is key for discovery, characterization of new enzymes, and production that will ultimately lead to low cost conversion of lignocellulosic biomass into biofuels, biochemicals, and bio-sugars

\section{Acknowledgements}

The authors would like to thank Universiti Teknologi Malaysia for providing financial support by Research University Grant (Q.J130000.2645.11J95) and providing equipment and facilities.

\section{Conflict of interest}

The author declares no conflict of interest.

\section{References}

1. Ben-Iwo J, Manovic V, Longhurst P. Biomass resources and biofuels potential for the production of transportation fuels in Nigeria. Renewable and Sustainable Energy Reviews. 2016;63:172-192.

2. Popp J, Lakner Z, Harangi-Rákos M, et al. The effect of bioenergy expansion: Food, energy, and environment. Renewable and Sustainable Energy Reviews. 2014;32:559-578.

3. Potumarthi R, Baadhe RR, Bhattacharya S. Fermentable sugars from lignocellulosic biomass: technical challenges. In Gupta VK, et al. editors. Biofuel Technologies. Berlin Heidelberg, Germany: Springer; 2013. p. $3-27$.

4. Bajpai P. Structure of Lignocellulosic Biomass. Pretreatment of Lignocellulosic Biomass for Biofuel Production. Singapore: Springer Briefs in Molecular Science; 2016. p. 7-12.

5. Merrettig Bruns U, Sayder B. Pre-treatment with Ammonia A2. In: Mussatto SI editor. Biomass Fractionation Technologies for a Lignocellulosic Feedstock Based Biorefinery. Amsterdam, Netherlands: Elsevier; 2016. p. 461-481.

6. George J, Sabapathi SN. Cellulose nanocrystals: synthesis, functional properties, and applications. Nanotechnol Sci Appl. 2015;8:45-54.

7. Lupoi JS, Seema Singh, Parthasarathi R, et al. Recent innovations in analytical methods for the qualitative and quantitative assessment of lignin. Renewable and Sustainable Energy Reviews. 2015;49:871-906.

8. Anwar Z, Gulfraz M, Irshad M. Agro-industrial lignocellulosic biomass a key to unlock the future bio-energy: A brief review. Journal of Radiation Research and Applied Sciences. 2014;7(2):163-173.

9. Carneiro T, Timko M, Prado J, et al. Biomass pre-treatment with carbon dioxide. Biomass Fractionation Technologies for a Lignocellulosic Feedstock Based Biorefinery. Amsterdam, Netherlands: Elsevier; 2016. p. 385-407.

10. Corredor DY, Salazar JM, Hohn KL, et al. Evaluation and characterization of forage sorghum as feedstock for fermentable sugar production. Appl Biochem Biotechnol. 2008;158(1):164-179. 